\title{
Social metabolism analysis using emergy
}

\author{
"Enrique Ortega \& ${ }^{* *}$ Miguel Juan Bacic
}

${ }^{*}$ Food Engineering School, ${ }^{* *}$ Economy Institute, State University of Campinas, Campinas, SP, Brazil, e-mail: ortegaunicamp@gmail.com

\begin{abstract}
After studying ecosystems and biosphere function for decades, Howard T. Odum sketched a methodology for calculating the value of the biophysical resources of nature and also the products of human activity. The methodology of "emergy" or "solar energy previously added" measures the biophysical work embedded in processes that use geological and biological resources and also human labor. According to Odum, the economic value (price) and the biophysical value (work added) generally do not coincide, as the market ignores or does not consider all factors of production. This paper explains the analysis of production-consumption systems using the emergy and discusses its potential utility in sustainable regional planning.
\end{abstract}

Key words: emergy, sustainability, collapse, resilience.

\section{Introduction}

There are two main lines of thought in relation with the concept of value and its measurement. The first considers only objective factors (the agriculture systems work according with the French Physiocrats or human labor in the vision of Adam Smith, David Ricardo and Karl Marx) and the other one believes that value is subjective (the apparent utility to the user). The theoretical proposal of Howard T. Odum (1924-2002) considers human labor value and also the work made by nature. Thus: emergy of a resource is its integral labor-value.

Emergy is defined as the potential energy (exergy) used directly and indirectly in the production of a resource. Emergy is expressed in solar equivalent Joules (seJ) per unit of resource $(\mathrm{kg}, \mathrm{J}$, etc.) or in terms of equivalent dollars per unit of resource.

The emergy value is valid when the calculation considers all the inputs and outputs that are part of the production. Generally, in addition to the main product, there are co-products which should not adversely affect other systems. In other words, the environmental and social costs (negative externalities) must be considered in the analysis of a production system.
The emergy methodology is a scientific approach based on Open Systems Thermodynamics that allows us to understand how the natural and the anthropic ecosystems throughout history function within the biosphere. This methodology lets us comprehend issues that challenge the economists: the ecological basis of sustainability, the calculation of support capacity and resilience of different regions, the energy intensity of different lifestyles, the complete energy and mass balance of production and consumption systems, and the impact absorption area, among others.

The aim of this paper is to introduce biophysical and economical processes analysis from the emergy methodology perspective, while clarifying the relationship between cities and their support areas.

\section{The method of systems' representation}

Diagrams of physical, biological and economic processes are used to clarify the reasoning behind analysis of systems, using a systems language developed by H. T. Odum (1994). Every language has symbols that are organized to express the sense of a phenomenon. The diagrams show 


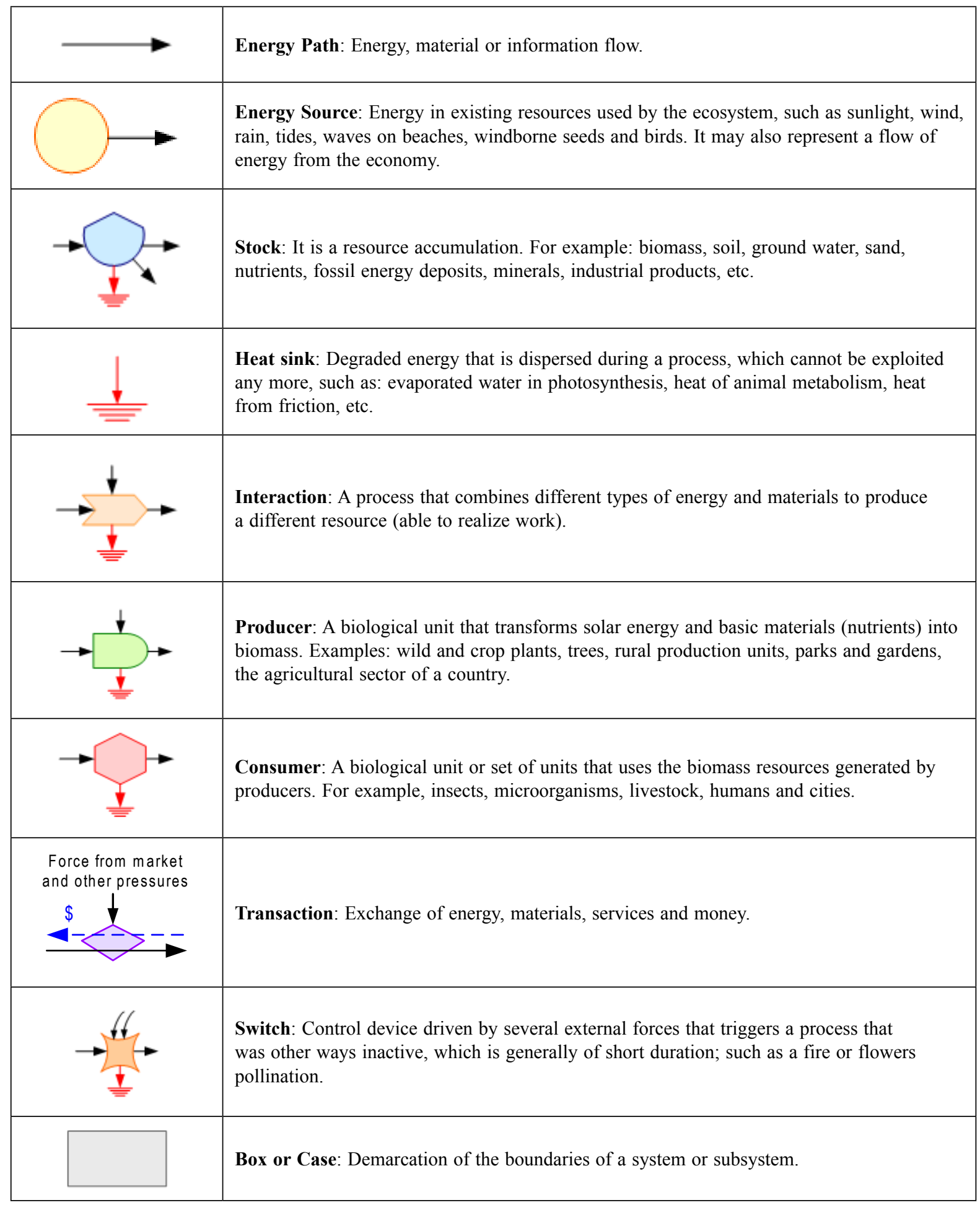

Figure 1. Symbols of the emergy methodology language (H. T. Odum 1996) 


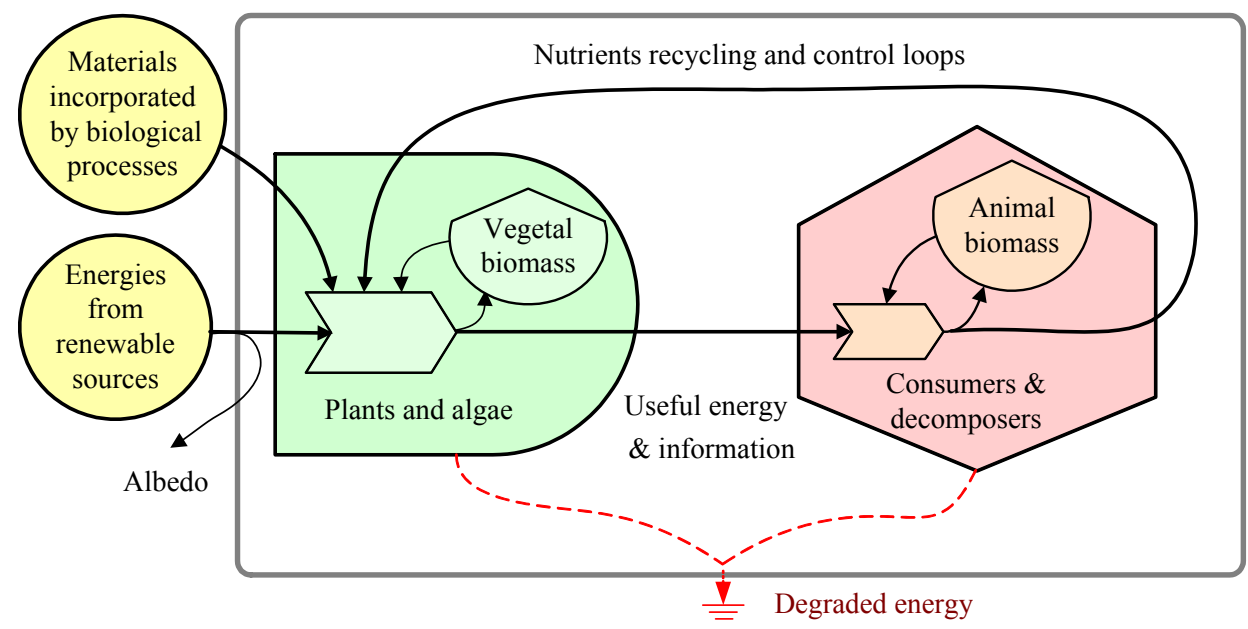

Figure 2. Simplified food chain

the interactions between external forces and internal components that use the energy potential in sustaining the system and the production of new resources.

\section{Production, Consumption and Recycling in Nature}

Figure 2 shows a sustainable biological system where the vegetable biomass is consumed by animal consumers who then return basic nutrients to plants. This system is able to increase its capacity to use available external energy according to the internal structures that it develops over time; these internal structures also determine the limits of the system's growth.

In order to use available resources, biological self-organized units form networks of producers and consumers that develop ties of energy, matter and information. The survival of these systems depends on the quality of these interactions. The food chain constitutes an ecosystem metabolism where biomass production is slow and consumption occurs as a rapid pulse.

\section{Economic relationship between the coun- tryside and the city using currency}

After the discovery of agriculture, rural areas were modified by humans who replaced the natural flora and fauna by introducing crops, eliminating local wildlife. Rural production is affected by innovations and external pressures. In some cases, traditional community producers can survive. Rural producers can self-organize or be organized by a third party; in this case, the advantages are distributed between them and the organizer (Fig. 3). If the farmers destroy natural stocks, the soil loses its fertility, biological productivity is reduced and eventually the farming system can collapse.

With urbanization (Figs. 4, 5 and 6) a clear separation between rural producers and urban consumers begins to develop, where it is no longer is possible to barter. Currency facilitates exchanges and increase commerce. As the economy grows, trade can become unfair, because urban groups with organizational skills have a greater bargaining power. Urban traders expand their purchasing power and press farmers for lower prices, transferring wealth to the city over time. The farmers' organization can reduce this transfer. Many times, producers seek solutions for their economic problems that involve the generation of negative externalities.

Rural systems rich in soil and water allowed the growth of networks of villages and cities. Distribution of income within the city is generally uneven and is concentrated in the top of the hierarchical chain of resources transformation. In the last three centuries, the global economic system became increasingly intensive in the use of nonrenewable resources and also in the predatory use of renewables, not replenishing stocks. For the urban economy these resources have a minimal cost, because it considers only resources removal cost without considering replenishment or recovering costs. With these subsidized resources, the urban industries produce low-cost agricultural inputs. Fertilizers and biocides replace the work of nature and man at farms, but, at the same time, biodiversity is destroyed and as result there is a decline in ecosystem services. When fossil fuels were incorporated by modern economies, central cities and central countries increased their dominance over peripheral areas, along with wealth transference. At the same time social and ecological problems were created. Natural ecosystem resilience is limited; humanity can go beyond the capacity of recovering. 


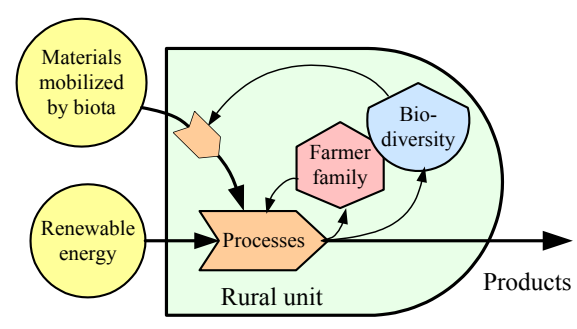

Figure 3a. Individual farmer

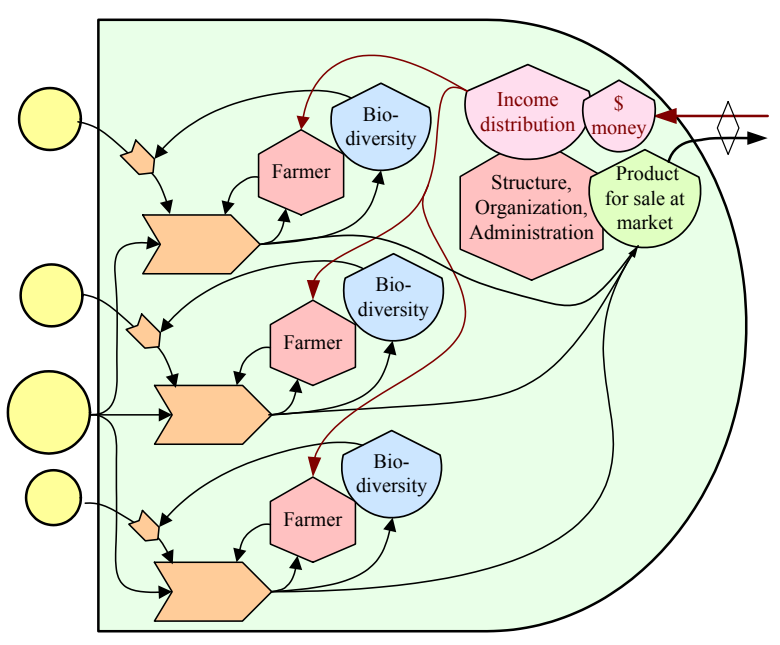

Figure 3b. Associated farmers

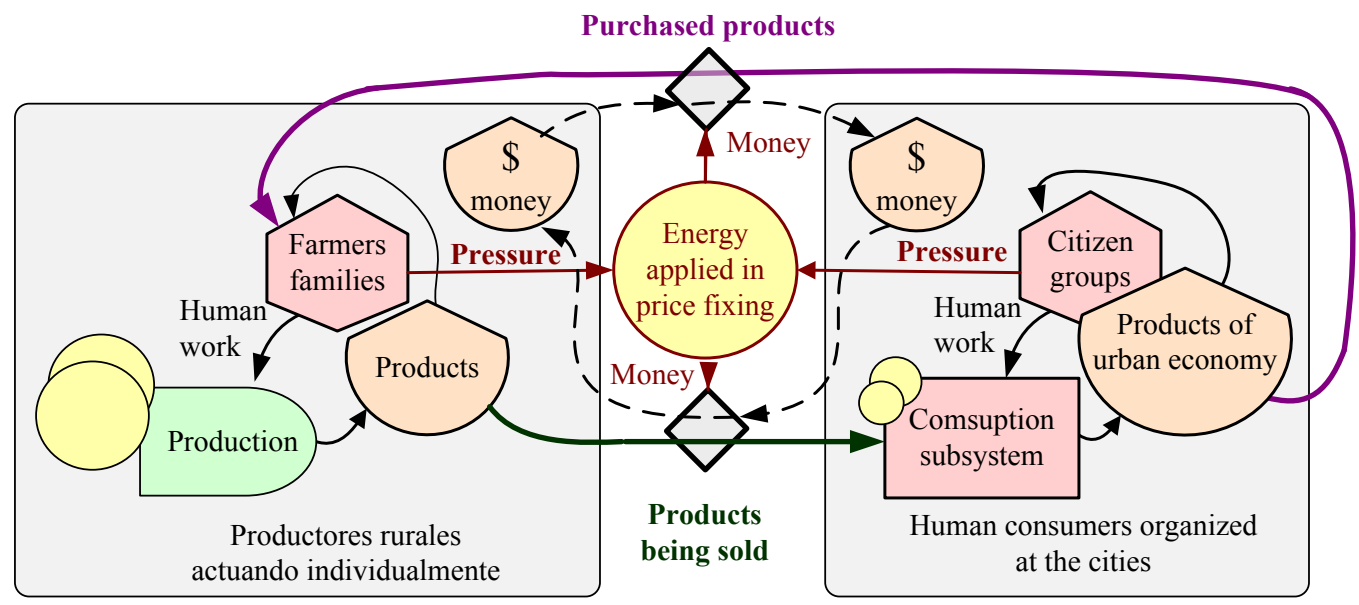

Figure 4. Country-city relationship with use of currency

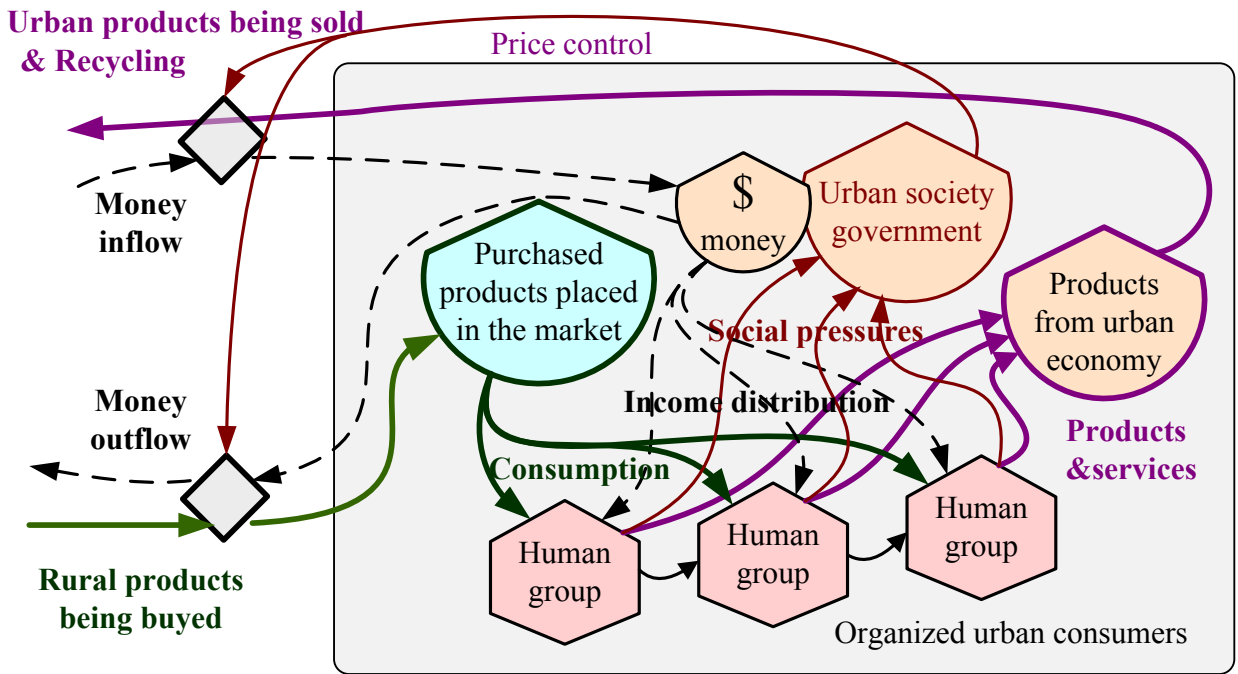

Figure 5. Relationship of city center to pressure for the appropriation of income 


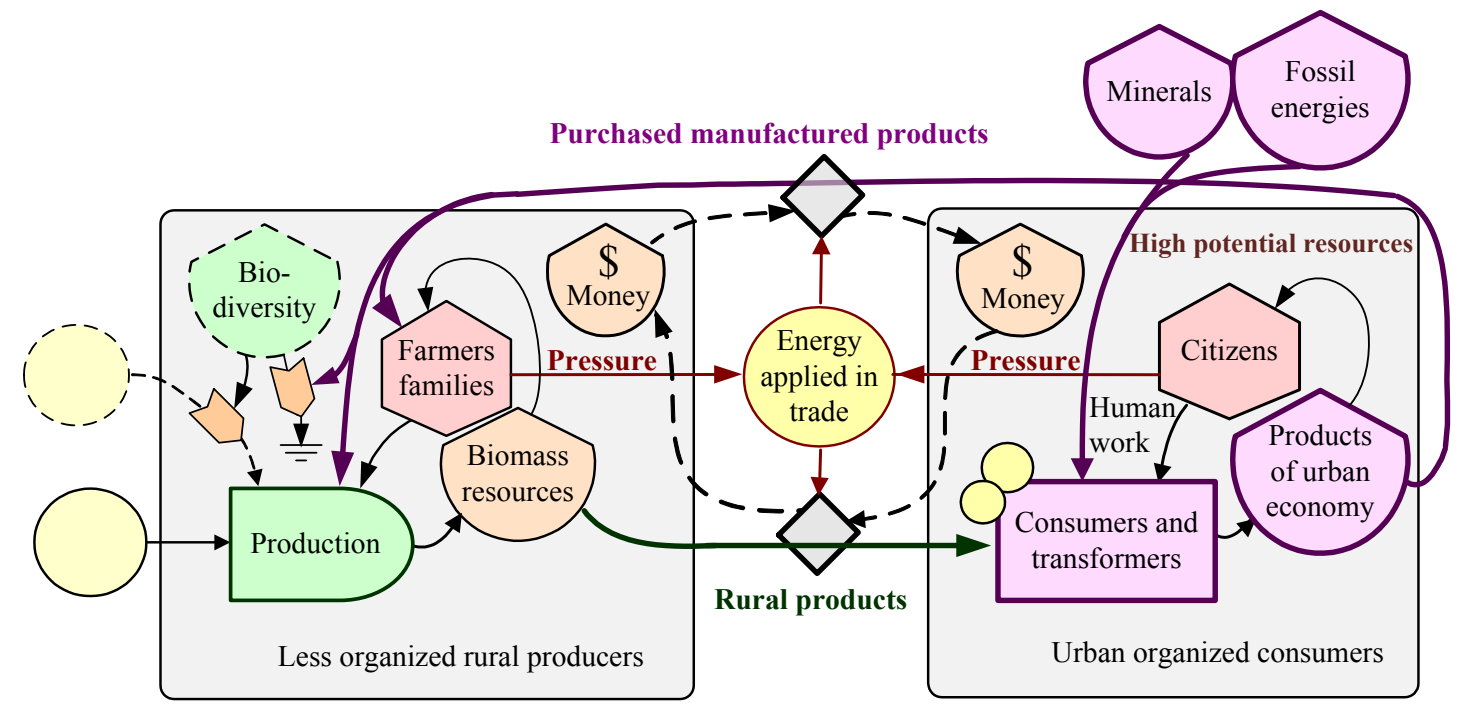

Figure 6. Country fields-city relationship influenced by petroleum products and minerals

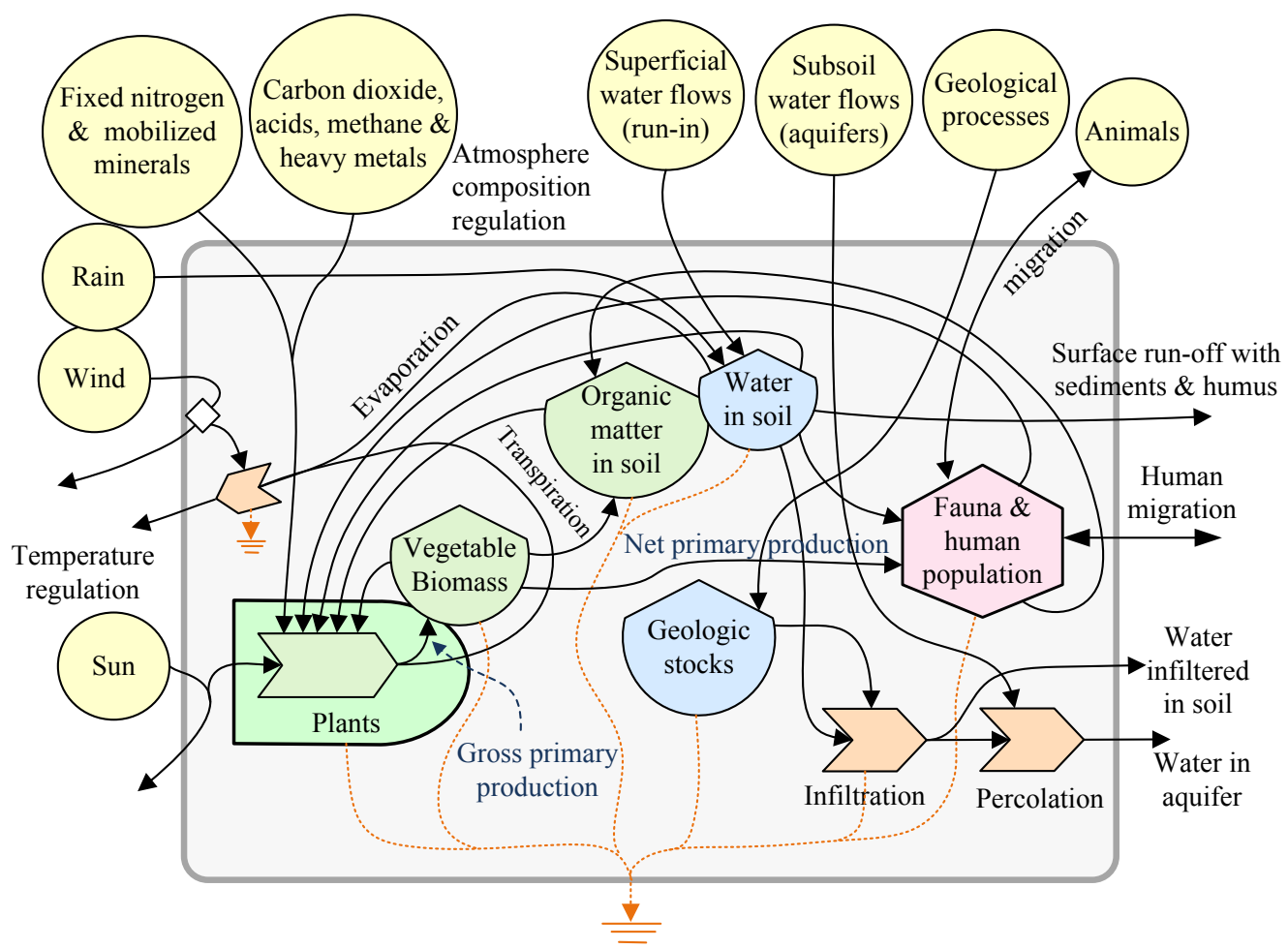

Figure 7. Relationship of a city with its support region. (Adapted from a diagram made by The Center for Environmental Policy, University of Florida)

\subsection{Analysis of a city (economic system) within a region (ecological system)}

A region is a complex system as Fig. 7 shows. Every city needs areas for environmental services provision and for impact absorption. Urban and Regional Planning should consider these geographical spaces.

\section{Analysis of an economic process within the biosphere}

Economic processes became more intense when mankind developed the ability to use coal, oil and gas. These resources have a huge energy density, since their formation took millions of years (Figs. 8 and 9). Petrochemical-based 


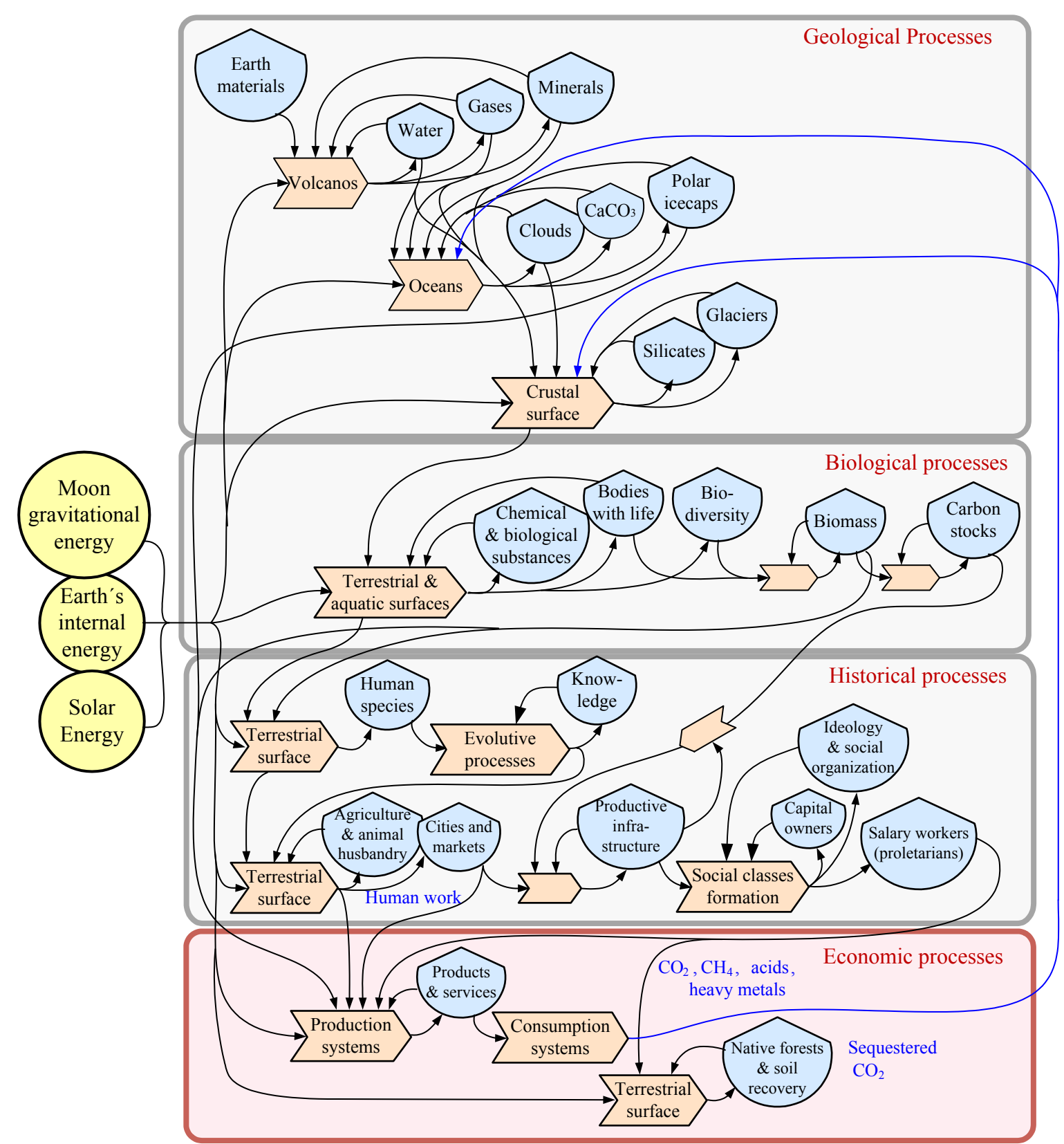

Figure 8 . The biosphere economic, geological, biological and cultural processes

fertilizers allowed farming to break beyond the limits of nutrient recycling. The work of nature and human was replaced with very high environmental and social costs that are ignored by most (Ortega et al. 2005). Conventional economic analysis is focused on monetary profit and also - in a hidden form- is focused on ideological control, and it cannot incorporate, in an adequate form, the ecological and social issues. Therefore, conventional economic analysis is unable to account for global warming, oil depletion, biodiversity loss, population concentration, $\mathrm{CO}_{2}$ biological sequestration, pollution with toxic substances, fresh water availability reduction, economic and political power concentration, rural exodus, and marginalization. The solution for all these negative externalities demands a change in the culture and in the social mode of production and consumption.

In the diagram below, the biosphere systemic model is shown with a historical perspective to highlight the contributions of nature and human beings to production processes.

Our current economies are linked through fossil fuels to work made by nature in other times through ancient geo- 


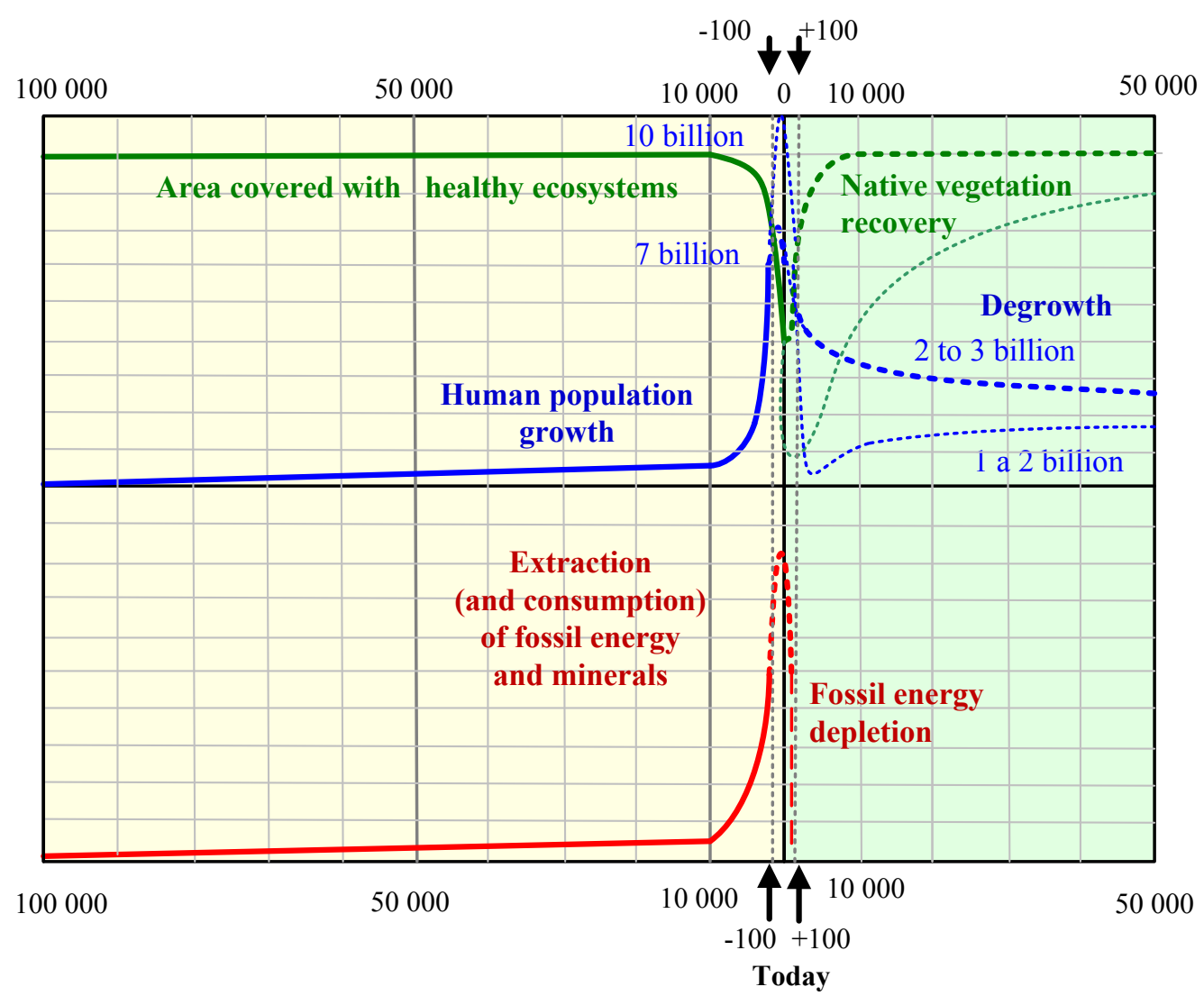

Figure 9. Simulation model of the biosphere (own calculations)

logical and biological work that generated sequestered carbon and biodiversity and social work that produced culture. Geological, biological and cultural stocks generate flows that make possible human life on the planet; the maintenance of those stocks requires significant feedbacks. Oil depletion can bring a sharp decline in population, given the global dependence on it (Odum \& Odum 2000, 2001).

Global stocks of natural resources, although finite, have been used intensively. Their monetary market price is very small compared with its real value. This blind spot is leading to a collapse of the biosphere and the human economy.

\subsection{Emergy analysis and public policy}

Emergy methodology can help to calculate rational, real prices through a structure of relative prices in the economic system. When resources are abundant, the economy trends to mobilize them as quickly as possible. When high-quality stocks become scarce, economic activity becomes more diversified and less intensive. As the availability of resources varies over time, policies must change in each stage of evolution. To guarantee resources for the future we must recognize the work of nature and invest in its recovery and preservation so that nature can continue to provide environmental services.

\section{Analysis of alternative production systems using emergy}

The current Growth Economy degrades and reduces environmental services. It serves the interests of central countries, causes social erosion, and concentrates power and property while benefits are exported. The current economy produces only a small number of rural jobs of poor quality and greenhouse gases.

The alternative model ("Rural Integrated Ecological Systems") is shown in Figures 10 and 11; it is based on the integrated production of food, biomass energy and environmental services for human decentralization and environment recovery. This proposal (Bacic et al. 1988) allows decentralization and can support a new network of smaller cities. Its design should consider the absorption of carbon dioxide, temperature and water regulation, biodiversity preservation, incorporation of unemployed people, carbon sequestration. 


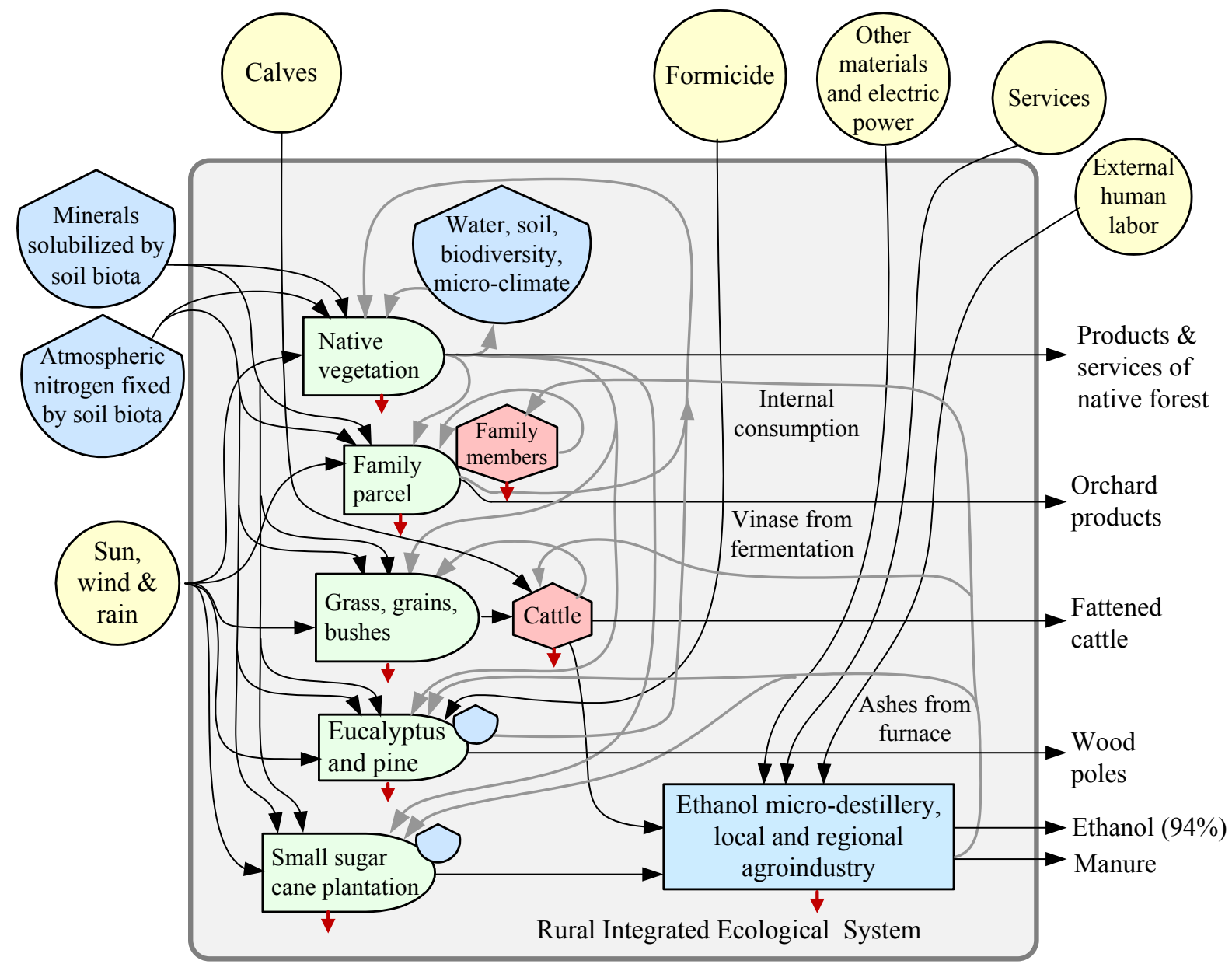

Figure 10. System of food production, energy and environmental services (Ortega 2008)

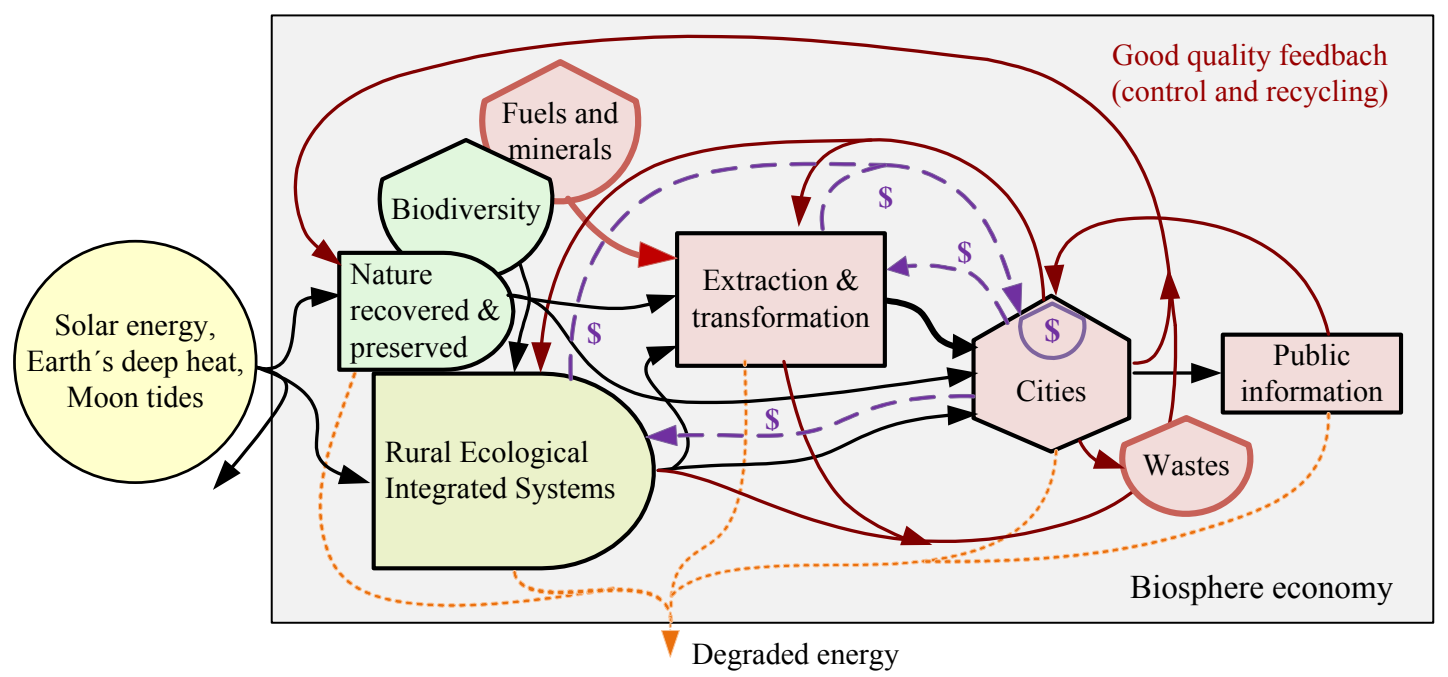

Figure 11. Sustainable interactions between city and country fields (adapted from Odum 2007) 


\section{Discussion}

With heavy use of fossil fuels, potential energy drives the flows of nature and economy in a biospheric engine that is designed and controlled by humans. Yet our oversimplified vision of an economic system composed of monetary flows and stocks fails to recognize the importance of energy flows, and this simple world view should be replaced by a better one, composed of emergy flows and stocks.

Emergy analysis allows a critical study of ecological-economical systems and allows us to calculate resources values to clarify whether a market price is correct or imbalanced in valuing nature's contributions. This information is essential in developing public policies that incorporate emergy value in the price, either through taxation or rationing, to guarantee that replacement of what was removed, to maintain natural fertility and to ensure future sustainability and governance.

\section{References}

Bacic M., Carpinteiro J., Costa Lopes C. \& Ortega E., 1988, Proposta para o estudo de um novo modelo de empresa agroindustrial, II Encontro Brasileiro de Energia para o Meio Rural, UNICAMP, Campinas.

Odum H. T., 1994, Ecological and General Systems: An Introduction to Systems Ecology, Univ. Press of Colorado, Niwot, USA.

Odum H. T., 1996, Environmental Accounting: Emergy and Environmental Decision Making, Wiley, New York, USA.

Odum H. T., 2007, Environment, Power and Society for the Twenty-First Century: The Hierarchy of Energy, Columbia University Press, USA.

Odum H. T. \& Odum E. C., 2000, Modeling for All Scales, An Introduction to Simulation, Academic Press, San Diego, CA, USA.

Odum H. T. \& Odum E. C., 2001, A prosperous way down: principles and polices, University Press of Colorado, Boulder.

Ortega E., Cavalett O., Bonifácio R. \& Watanabe M., 2005, Brazilian soybean production: Emergy analysis with an expanded scope, Bulletin of Science, Technology and Society, Toronto 25(4): 323-334.

Ortega E., 2008, Novo modelo de produção agrícola: SIPAES, Fórum Sustentar, Campinas, http://www.unicamp.br/fea/ortega/coeduca/SIPAES-Ortega.ppt. 